\title{
Can Epitheliazed Graft Be Used to Achieve Absolute Root Coverage When Combined with Coronally Advanced Flap (CAF) for a Case of Gingival Recession? - A Case Report of a Mandibular Molar
}

\author{
Sarah Mariam* and Firdous Ahmad Najar \\ Department of Periodontology, Bharati Vidyapeeth (Deemed to be University), India
}

\begin{abstract}
Gingival recession poses a multitude of problems like root sensitivity, plaque accumulation, root caries and other functional problems. Treatment options range depending on the type of recession to the condition of mucogingival tissues. Connective tissue graft in combination with coronally advanced flap has been described as a gold standard in treatment of gingival recession. This case report describes a case of absolute root coverage achieved with epithelialized graft (which was subsequently de-epithelialized) when combined with coronally advanced flap for a case of gingival recession in a Mandibular molar.
\end{abstract}

Keywords: Epithelialized graft; Coronally Aadvanced; Root coverage

\section{Introduction}

Gingival recession is defined as the migration of the marginal gingiva from the Cement Enamel Junction (CEJ) to a more apical position. The causes could be periodontal, iatrogenic, soft tissue

OPEN ACCESS

*Correspondence:

Sarah Mariam, Department of

Periodontology, Bharati Vidyapeeth (Deemed to be University), Dental

College and Hospital, Pune, Maharashtra, India, Tel: 9540068535;

E-mail: sarahmariam24@gmail.com

Received Date: 20 Apr 2020

Accepted Date: 02 Jun 2020

Published Date: 04 Jun 2020

Citation:

Mariam S, Najar FA. Can Epitheliazed

Graft Be Used to Achieve Absolute

Root Coverage When Combined with

Coronally Advanced Flap (CAF) for a

Case of Gingival Recession? - A Case

Report of a Mandibular Molar. J Dent

Oral Biol. 2020; 5(2): 1165.

ISSN: $2475-5680$

Copyright $\odot 2020$ Sarah Mariam. This is an open access article distributed under the Creative Commons Attribution

License, which permits unrestricted

use, distribution, and reproduction in any medium, provided the original work is properly cited. factors, habits or mechanical factors [1]. The treatment of gingival recession on the buccal aspect in posterior teeth is a necessity because of functional aspects (sensitive roots, root caries) or esthetic concern. Here we present a case report which describes a case of absolute root coverage achieved with epithelialized graft (which was subsequently de-epithelialized) when combined with coronally advanced flap for a case of gingival recession in a mandibular molar. Connective tissue graft in combination with coronally advanced flap has been described as a gold standard in treatment of gingival recession [2].

\section{Case Presentation}

A 22-year-old male patient came to the Department of Periodontology, Bharati Vidyapeeth (Deemed to be University), Dental College and Hospital, Pune, Maharashtra, India with the chief complaint of sensitivity on having cold food in right lower back tooth region since 2 months. On clinical examination, gingival recession was noted in mandibular right first permanent molar on buccal surface only with vertical component around $4 \mathrm{~mm}$, probing depth $2 \mathrm{~mm}$, adequate width of attached gingiva with normal vestibular depth. No mobility was associated with the tooth. Patient was systemically healthy. Diagnosis was Miller's class gingival recession. Treatment blood investigations were done. Etiotropic phase was completed and after 2 weeks surgical therapy was carried out. Written informed consent was obtained from patient and procedure explained. Local anesthesia was administered (1:80000) by inferior alveolar nerve block and buccal nerve block. Preparation of recipient site was done by first curetting the area and thereafter application of tetracycline for root bio-modification. Crevicular incision was given on the tooth and one tooth mesial and distal to it as well. Thereafter reflection of full thickness flap and partial thickness flap was reflected beyond the mucogingival junction (Figure 1,2). This was done so as to coronally advance the flap. Dual surgical site (the donor site) was created in the region of bicuspids on the palatal mucosa. Greater palatine nerve block as well as local infiltration was given to procure the epithelialized graft (Figure 3,4). It was subsequently de-epithelialized, so that only connective tissue remained (Figure 5). Hemostatic agent, collagen sponge was applied at the donor site and sutured with 4 to 0 mersilk (Figure 4). Adequate homeostasis was achieved. The de-epithelialized graft was placed over the recipient site, that is, the denuded root surface and suturing was completed using 

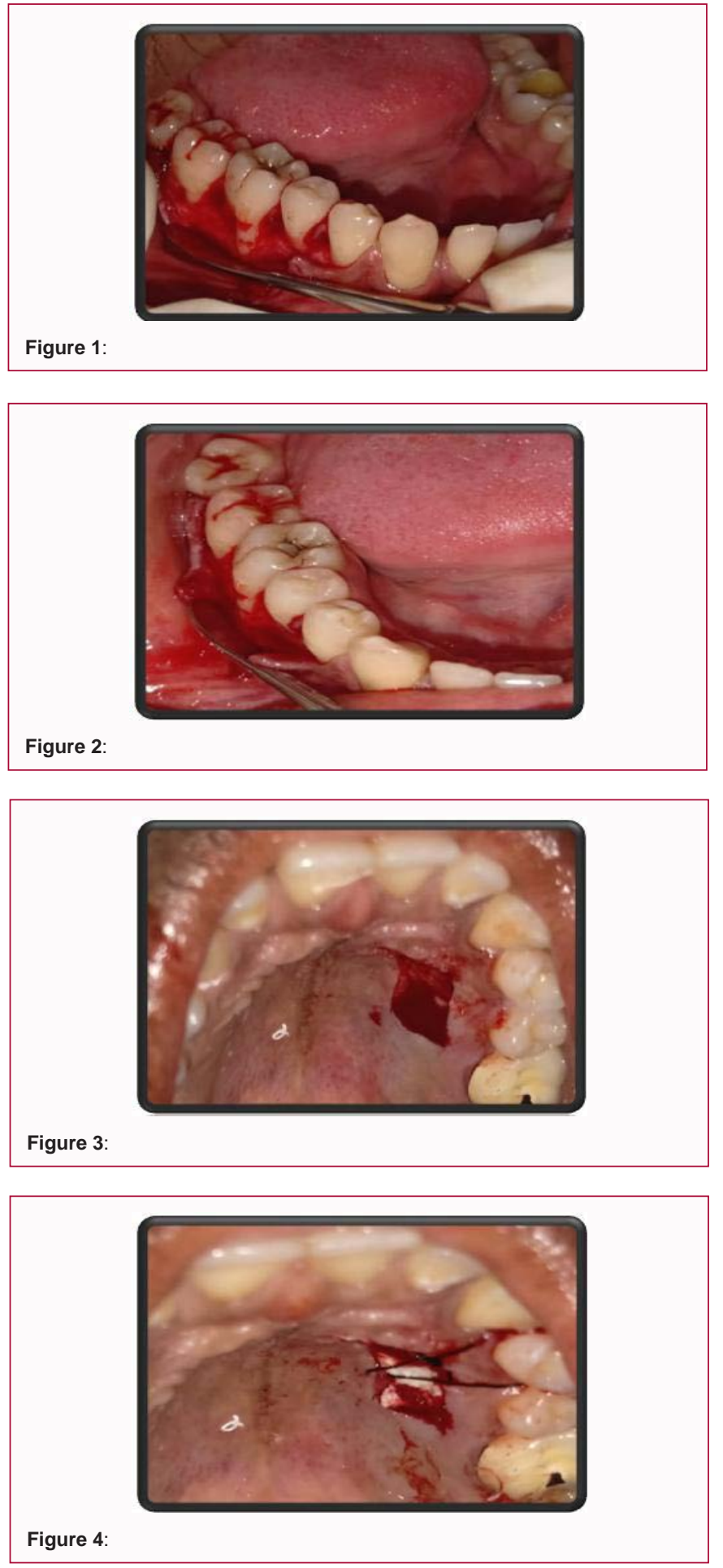

absorbable suture (vicryl 4-0) (Figure 6). At the recipient site, flap was coronally advanced so that it completely covered the graft without creating an excessive muscular tension in the alveolar mucosa and vestibule. It was sutured in this position with 4-0 vicryl (Figure 7). Periodontal dressing was applied to the recipient site. Analgesics and antibiotics were prescribed to the patient for five consecutive days post surgery. Oral hygiene instructions were given. The patient was recalled 10 days postoperatively to assess healing and for removal sutures and periodontal dressing. Root coverage was achieved by 2 weeks. Healing was satisfactory (Figure 8 ). Complete root coverage was achieved. Results at 6 months (Figure 9,10).
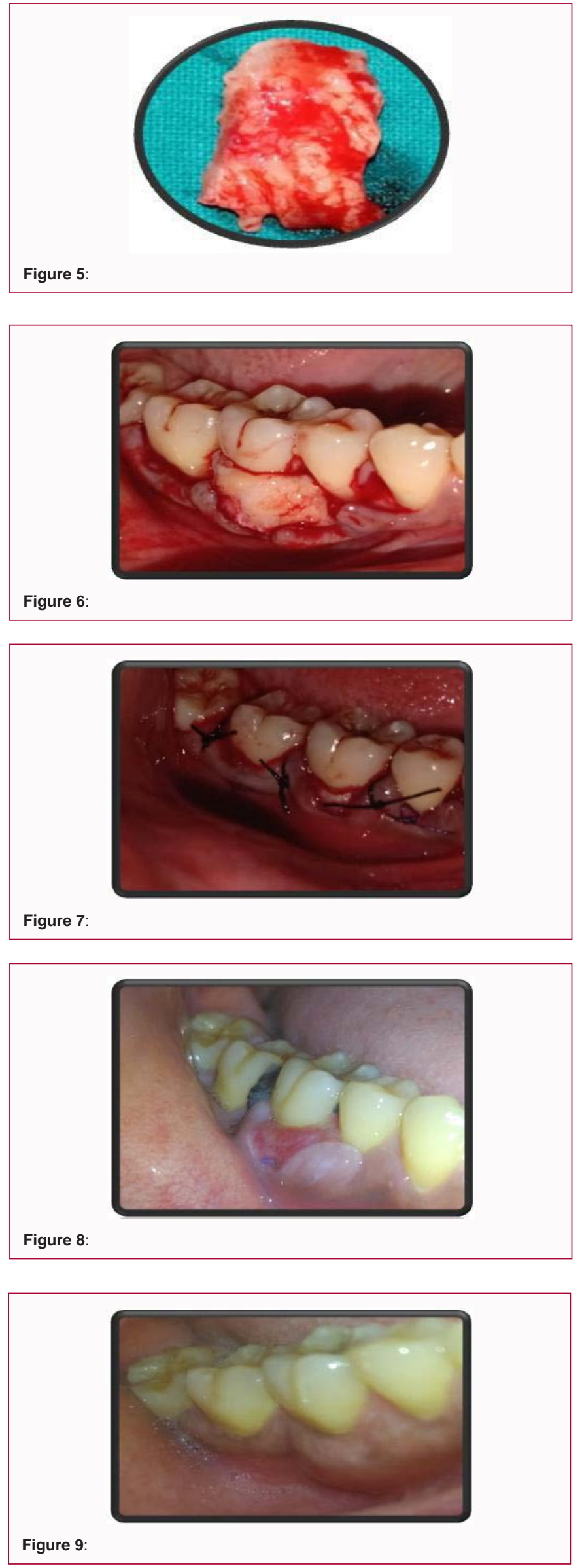


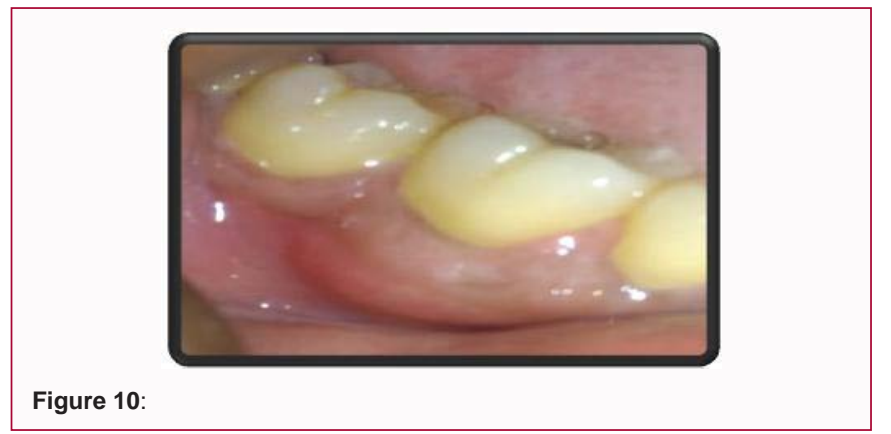

\section{Discussion}

The rationale for periodontal plastic surgery includes the triad of restoration of health, function and esthetics of periodontium. This can be achieved by various augmentation and corrective procedures. Various surgical techniques to achieve root coverage include free gingival grafts, pedicle flaps such as lateral pedicle, advanced flaps like semi lunar flaps, coronally repositioned flaps, connective tissue grafts, sub-epithelial grafts, guided tissue regeneration, use of platelet rich fibrin and use of some alloplastic materials as well [3]. A procedure which is a winner among all the less achievers is the use of connective tissue graft with coronally advanced flap for root coverage [4]. The reasons for its higher rate of clinical success could be attributed to similar genetic make-up, dual vascular anastomosis to the graft, better 0 esthetics; greater healing potential in the donor site, incredible color matching, and morbidity in donor site is less, all of which achieve better clinical results [5].

\section{Conclusion}

This case report infers that when proper technique is applied with right patient selection then complete root coverage doesn't remain an enigma for dental professionals. Very predictable results can be achieved with connective tissue graft in combination with coronally advanced flap.

\section{Acknowledgement}

I would like to acknowledge the contribution of our surgical team.

\section{References}

1. Bittencourt S, Ribeiro Edel P, Sallum EA, Sallum AW, Nociti FH Jr, Casati MZ. Root surface biomodification with EDTA for the treatment of gingival recession with a semilunar coronally repositioned flap. J Periodontol. 2007;78:1695-701.

2. Cairo F, Pagliaro U, Nieri M. Treatment of gingival recession with coronally advanced flap procedures: A systematic review. J ClinPeriodontol. 2008;35(8)136-62.

3. Oates TW, Robinson M, Gunsolley JC. Surgical therapies for the treatment of gingival recession. A systematic review. Ann Periodontol. 2003;8(1):30320.

4. Pini-Prato G, Nieri M, Pagliaro U, Giorgi TS, Marca ML, Franceschi D, et al. Surgical treatment of single gingival recessions: Clinical guidelines. Eur J Oral Implantol. 2014;7(1):9-43.

5. Cortellini P, Pini Prato G. Coronally advanced flap and combination therapy for root coverage. Clinical strategies based on scientific evidence and clinical experience. Periodontol. 2000-2012;59(1):158-84. 